\title{
Política pública de preservação ferroviária em Bauru (SP): os desdobramentos da criação de programas nacionais e conselhos representativos na década de 1980
}

\author{
Public policy of railway preservation in Bauru (SP): the \\ consequences of creation of national programs and \\ representative councils in the 1980 s
}

\author{
Enviado em: 17/04/2018 \\ Aceito em: 28/07/2018 \\ Sérgio Ricardo Losnak ${ }^{1}$ \\ Eduardo Romero de Oliveira ${ }^{2}$
}

\begin{abstract}
Resumo:
Este trabalho busca caracterizar as políticas públicas de preservação no estado de São Paulo, mais especificamente da cidade de Bauru, tendo como objetos o Conselho de Defesa do Patrimônio Cultural e o Museu Ferroviário Regional. Esses mecanismos de proteção estão presentes em muitos municípios e se tornaram a principal ferramenta de preservação de bens ferroviários. Em termos metodológicos, o trabalho contou com pesquisa bibliográfica exploratória sobre o tema, análise documental e entrevistas com agentes envolvidos no processo. Como resultado, chegou-se à compreensão das diretrizes, conceitos, valores e agentes que atuam na preservação por meio das políticas públicas, indicandonos o método de museificação como prática principal quando se trata do patrimônio industrial ferroviário, não só na cidade de Bauru como em outros municípios do estado de São Paulo.
\end{abstract}

Palavras-chave: Preservação.Patrimônio ferroviário. Museus e conselhos.

\begin{abstract}
:
This work aims to characterize the public policy of preservation in the state of São Paulo, more specifically of the city of Bauru, having as research object the Council of Defense of Cultural Heritage and Railway Regional Museum. These mechanisms of protection are in many municipalities and they have become the main tool for the preservation of railway goods. In metodological terms, the research was based on exploratory and bibliographic research on the subject, documental analysis and interviews with agents involved in the process. As a
\end{abstract}

\footnotetext{
${ }^{1}$ Mestrando, PPGARQ, Unesp Bauru. sergiolosnak@gmail.com

${ }^{2}$ Doutor, PPGARQ, Unesp Bauru. eduardo.romero.de.oliveira@gmail.com
} 
result, the guidelines, concepts, values and agents that acts in the preservation through public policies were found, indicating the method of museification as a main pratice in the case of industrial railway heritage, not just in Bauru city, but in other municipalities in São Paulo state.

Keywords: Preservation. Railway heritage. Museums and councils.

\section{Introdução}

Considerando que foi no período da história mais recente do Brasil que a preservação do patrimônio cultural passou ser difundida e institucionalizada de forma planejada pela União, estados e municípios é que podemos compreender as particularidades das ações que nortearam a preservação do patrimônio no país nos dias de hoje. Durante o Estado Novo (1937-1945), o governo de Getúlio Vargas instaurara uma ideologia de Estado Nacional, que se refletiu nas diferentes áreas de atuação do seu governo. No campo da cultura, dá-se início à implantação de uma política pública de proteção do patrimônio histórico nacional pelo reconhecimento de determinada identidade, buscando de forma autocrática e conservadora uma suposta harmonia entre as classes sociais, em vista do reconhecimento do trabalho e do caráter mestiço do povo brasileiro (RUBIM, 2007).

Assim, passamos a considerar que este seja o marco inicial das políticas públicas para a cultura desenvolvida pelo Estado brasileiro (RUBIM, 2007; BOTELHO, 2007; BARBALHO, 2007), e que a preservação patrimonial, alicerçada basicamente pelo instrumento jurídico do tombamento, tornou-se uma ferramenta primordial na implantação do projeto ideológico do governo da época.

Essa política só se altera de forma significativa diante da promulgação da Constituição de 1988, que de certa forma amplia e aprofunda as práticas e o conceito de preservação no Brasil, e passa a considerar patrimônio cultural os bens materiais e imateriais que se referem à memória dos diferentes grupos da sociedade brasileira, compreendendo suas formas de expressão; aos modos de viver, criar e fazer; a bens materiais, como obras de arte, objetos, documentos, edificações e espaços destinados às manifestações artísticas e também os conjuntos urbanos e sítios de valor histórico, paisagístico, artístico, arqueológico, paleontológico, ecológico e científico (BRASIL, 1988). Assim, aquele esforço institucional de identidade unívoca cede lugar ao reconhecimento da diversidade plural da memória social do povo brasileiro e atribui 
não só aos demais entes federativos como também à sociedade civil e à iniciativa privada a prerrogativa de atuar no âmbito do patrimônio cultural.

A ampliação das concepções oficiais sobre o patrimônio cultural avançou substancialmente na primeira década dos anos 2000, quando o Ministério da Cultura implementou uma política cultural mais estruturada, que reconheceu a cultura imaterial, organizou uma rede de articulação democrática do setor cultural no país, por meio das conferências de cultura e câmaras setoriais, tendo como resultado o Plano Nacional de Cultura, e criou o Instituto Brasileiro de Museus, órgão que recebeu atribuições relacionadas à política nacional de museus.

Contudo, o que vem a ser uma política cultural? Segundo Teixeira Coelho (1999), trata-se do conjunto de intervenções do Estado, da sociedade civil e da iniciativa privada em satisfazer as necessidades culturais e promover 0 desenvolvimento de suas representações simbólicas. Essas iniciativas buscam planejar, produzir, difundir e preservar as diferentes formas de cultura e do patrimônio histórico por meio de intervenções diretas de ação cultural e de normas jurídicas. Assim, as políticas culturais devem buscar o fortalecimento da produção,difusão, formação e o consumo cultural, tendo a cultura como finalidade última (BARBALHO,2013).

As discussões pertinentes ao patrimônio industrial no Brasil surgem no início da década de 1970 (AZEVEDO, 2010). Apesar de ser algo recente, observa-se o mesmo caminho percorrido pelas demais tipologias de patrimônio, prevalecendo inicialmente a preservação arquitetônica monumental de grandes estruturas isoladas e, mais recentemente, agrega-se a ideia do conjunto e da inserção dos elementos imateriais. Essa situação pode ser verificada quanto ao patrimônio ferroviário, pois a preservação tem se restringido, na maioria das vezes, às estações, em detrimento às demais estruturas que proporcionam o funcionamento destas, além da negligência na preservação dos elementos imateriais associados às tecnologias, ao modo de produção e de vida dos trabalhadores.

Outra questão que deve ser destacada é que a arquitetura industrial ferroviária empregada no estado de São Paulo é um exemplar testemunhal do modo de produção cafeeiro paulista (OLIVEIRA, 2010a, 2011). Portanto, o seu processo de transformação em patrimônio, ocorrido por meio das políticas públicas do governo do estado, via Conselho de Defesa do Patrimônio Histórico, Arqueológico, Artístico e Turístico (Condephaat), buscou consolidar a identidade progressista paulista, 
proporcionada inicialmente pela cafeicultura e, mais tarde, pela industrialização. Assim, é por meio desse binômio que a política de preservação ferroviária, reduzida ao mecanismo de tombamento e musealização, tornou-se o principal método utilizado também pelos municípios paulistas (LOSNAK; OLIVEIRA, 2016).

É diante desse contexto que este trabalho irá discorrer sobre o processo de origem das políticas públicas de preservação do patrimônio ferroviário de Bauru.A metodologia utilizada parte do conhecimento. O método é exploratório e utiliza recursos como a pesquisa bibliográfica, documental, entrevistas e estudo de caso.

A cidade de Bauru possui particularidades relativas à sua formação recente, no final do século XIX, associadas ao desbravamento do sertão do Oeste Paulista e da instalação de um complexo industrial ferroviário (GHIRARDELLO, 1992). Como frente e suporte para a ocupação do Oeste, Bauru tornou-se "chão de passagem" (SANT'AGOSTINHO, 1995, p. 8), principalmente pela construção da Estrada de Ferro Noroeste do Brasil (Efnob) em 1905, que parte de Bauru e chega à cidade de Corumbá, estado de Mato Grosso do Sul, divisa territorial com a Bolívia, como também pela chegada dos trilhos de mais duas ferrovias que ligavam a cidade ao Porto de Santos - a Estrada de Ferro Sorocabana (1904) e a Estrada de Ferro da Companhia Paulista (1911) (SILVA, 1957). A cidade de Bauru abriga edificações expressivas com estilos variados, como eclético, art déco e moderno (SALCEDO, 2011). Localizada na região central do estado, atualmente possui cerca de 370 mil habitantes e tem sua economia baseada no comércio e em serviços, tendo sua produção rural atrelada ao agronegócio e à produção familiar.

Uma das primeiras ações de preservação ferroviária no município surge com a criação do Museu Ferroviário Regional de Bauru (MFRB), por meio da Lei n. 1.425, de 1969, que atribuía à prefeitura municipal a prerrogativa de "fiscalizar" o futuro museu, o qual se destinava a "acolher e preservar material ferroviário para exibição ao público". Houve um hiato de 20 anos entre a promulgação da referida lei, em 1969, e a abertura do MFRB ao público, no ano de 1989 (DIÁRIO DE BAURU, 1989), que acabou sendo viabilizada em parcerias com as empresas ferroviárias e o executivo.

Outro programa objeto de estudo deste trabalho, que atua desde a sua formação na proteção de bens ferroviários, é o Conselho de Defesa do Patrimônio Cultural de Bauru (Codepac), considerado o principal programa de preservação do patrimônio cultural implantado pelo município. Criado pela Lei Municipal n. 3.486, de 1992, a referida lei estabelece os objetivos do programa e confere ao conselho o papel 
de "definir" a política pública de defesa do patrimônio cultural da cidade, tendo o recurso do tombamento como principal ferramenta.

\section{Histórico das políticas de preservação em Bauru}

Desde o início das primeiras ações de preservação praticadas tanto pelo poder público como pelas entidades sociais e privadas no município, os objetos da indústria ferroviária local sempre estiveram presentes, o que demonstra a relação íntima da ferrovia com a memória coletiva da cidade. As empresas ferroviárias também atuavam internamente e de forma inexplícita, mantendo preservados objetos apreciáveis que demonstravam o processo de produção praticado no passado, como é o caso do mobiliário de madeira, das locomotivas a vapor e de muitos outros que se tornaram acervo do MFRB.

O primeiro museu criado na cidade foi o Museu Histórico Pedagógico Morgado de Matheus (MHPMM), do Serviço Estadual de Museus, que passou por um longo processo de formação. Segundo a revista local Realce, de setembro de 1969, essa tarefa ficou a cargo de uma das mais tradicionais universidades da cidade, que oferecia cursos para docência nas áreas de filosofia, história e geografia, e que atualmente é conhecida como Universidade do Sagrado Coração (USC).

\footnotetext{
Em 1956, o Diretor do Serviço Estadual de Museus da Secretaria de Educação, Dr. Vinicius Stein, vindo a Bauru para ministrar um curso de Museologia, declarou instalado oficialmente junto à Faculdade de Filosofia, Ciências do Sagrado Coração de Jesus, o Museu Histórico Pedagógico Morgado de Matheus, sendo nomeada diretora a Irmã Rosalva Motter, também diretora da Fafil, que teria sob suas responsabilidades a criação do Museu de Bauru, a partir da instituição burocrática (REALCE, 1969, p. 30).
}

Um dos primeiros exemplos da preservação ferroviária, com significado simbólico considerável, foi quando a locomotiva a vapor nํ 1 da Efnob, que parou de operar na primeira metade do século $X X$, transformou-se em acervo museológico do MHPMM, no ano de 1979. Os jornais da época mostram que objetos e documentos relativos à ferrovia sempre estiveram presentes no acervo MHPMM, basicamente formado por doações particulares e das empresas ferroviárias, que eram estimuladas por campanhas públicas (JORNAL DA CIDADE, 1979a, p.3; 1979b, p. 28; 1979c, p. 17; 1979d, p. 5; 1979e, p. 25). 
Com a criação de um museu histórico municipal na cidade (MHMB) pelo executivo, no ano de 1988, o museu estadual e o municipal passaram a funcionar juntos no mesmo espaço físico, levando à municipalização do acervo do MHPMM, ocorrida formalmente no ano de 1997 (MHMB, 2017). Assim, podemos afirmar que o museu estadual, MHPMM, foi o precursor na formação do acervo ferroviário na cidade de Bauru, abrindo as portas para a criação de um museu específico sobre a ferrovia.

Quanto à atuação do governo do estado no campo cultural, podemos destacar duas ações que contribuíram para construção da atual política de preservação ferroviária no município: a implantação da Oficina Cultural Glauco Pinto de Moraes, no ano de 1990, e o desenvolvimento do projeto Olhando para os Telhados.

A Oficina Cultural inicia seus trabalhos trazendo a temática ferroviária em exposições internas, externas e na figura de seu patrono Glauco Pinto (DIÁRIO DE BAURU, 1990, p. 1), artista plástico falecido no mesmo ano de criação do órgão, captando da indústria ferroviária, diante da diversidade de suas máquinas, o principal elemento utilizado em seu processo criativo. Essa fase artística é inaugurada nos anos de 1970 com pinturas realistas (Figura 1), a princípio tendo as locomotivas como referência, inspirando-se principalmente em suas diferentes peças.

Figura 1 - Pinturas de Glauco Pinto de Moraes. (a) "Engates Ferroviários Acoplados: Visão Superior", de 1978; (b) "Barras Vermelhas", de 1987

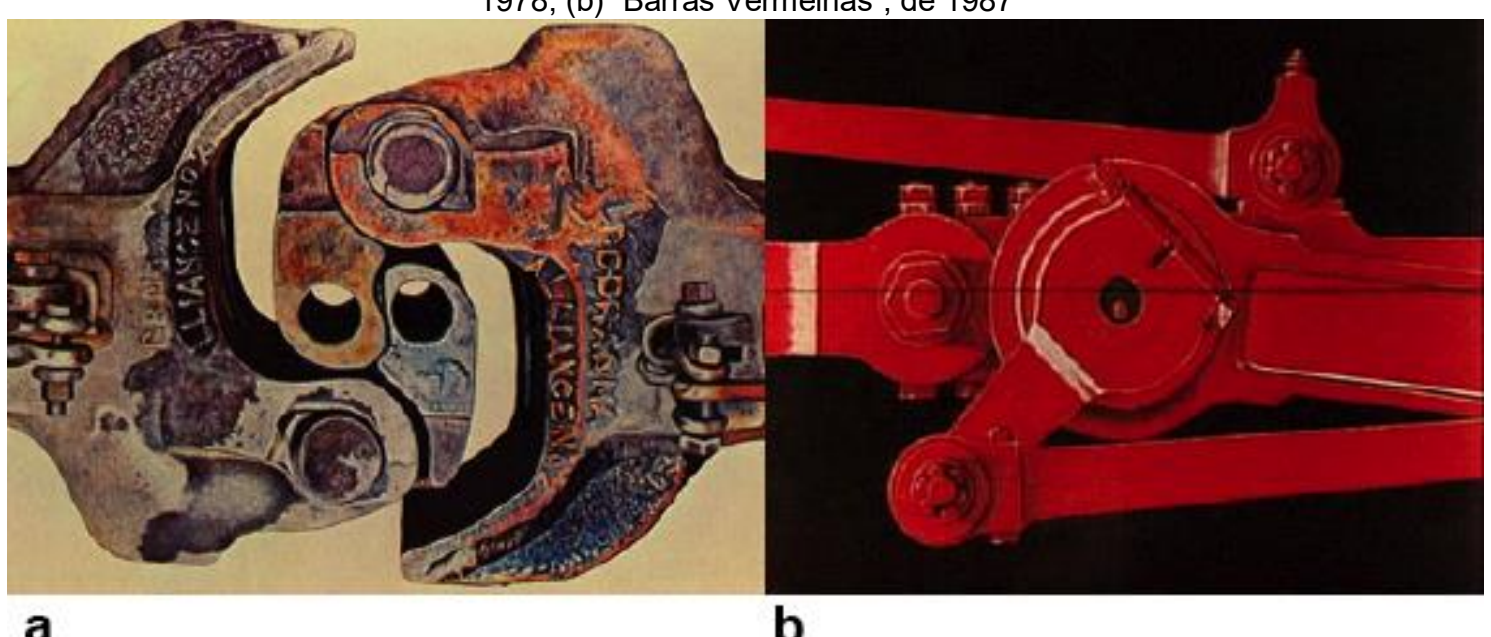

Fonte: Disponível em: <http://enciclopedia.itaucultural.org.br>.

Olhando para os Telhados foi um projeto regional envolvendo 38 municípios da região de Bauru, desenvolvido pela Divisão Regional de Ensino do Estado. Seu 
objetivo era incluir no ensino de história a possibilidade de os alunos vivenciarem a história local por meio da descoberta de sua própria cidade, utilizando a visita de campo como elemento de aprimoramento do olhar para os prédios localizados na região central das cidades participantes, gerando assim uma demanda de acesso às fontes primárias de pesquisa sobre os municípios, conforme explica a coordenadora do projeto,professora Lídia Possas.

\begin{abstract}
A ideia é que os próprios alunos viabilizem suas fontes de consulta antes de se debruçarem sobre a história local. Entre estas fontes estão a coleta de documentos, fotos de instituições e de entidades privadas da cidade; entrevistas com pessoas que experimentaram ou se aproximaram mais sensivelmente da história focalizada, além da observação in loco dos cenários dessa história, como o patrimônio arquitetônico. (Ou quem esqueceu que atrás dos tapumes da rua Batista de Carvalho respiram as fachadas arquitetônicas que têm a cara de Bauru do passado?) (JORNAL DA CIDADE, 1991, p. 5).
\end{abstract}

O patrimônio arquitetônico que representava o passado passou a ser identificado e observado por um número maior de pessoas. Dessa forma,constatou-se que este se encontrava em pleno processo de transformação diante das modificações urbanas que acometiam o centro da cidade de Bauru.

Alterações apontadas por Possas (2017) quando se refere aos tapumes da Rua Batista de Carvalho estão associadas à remodelação da Praça Rui Barbosa, à construção do calçadão da Rua Batista de Carvalho e diante da constatação de que estabelecimentos comerciais iniciavam um processo de renovação de suas fachadas. Essa situação, segundo Ghirardello (2017) e Possas (2017), foi um dos principais fatores que motivaram intelectuais, entusiastas da memória e políticos a trabalharem para a criação de mecanismos de proteção como o Codepac.

No âmbito das ações do governo municipal, a primeira ação concreta de preservação ferroviária aconteceu no ano de 1980, quanto a locomotiva a vapor 404 da Efnob (Figura 2), foi colocada em exposição no Bosque da Comunidade, localizado na região sul da cidade (JORNAL DA CIDADE, 1980). Trata-se, de certa forma, de uma patrimonialização dos vestígios da indústria ferroviária local, representante de um passado que durou até o início dos anos 1960, quando as locomotivas a vapor pararam de operar definitivamente na Efnob (PMB, 2017) e foram substituídas pelas locomotivas a diesel. Recuperada e cedida à Prefeitura Municipal de Bauru (PMB) pela Rede Ferroviária Federal S.A. (RFFSA), por meio do Termo de Permissão de Uso no 
689, de 3 de agosto de 1977 (PMB, 2017), a locomotiva foi tombada pelo conselho de preservação local em 2010, por meio do Decreto n. 11.378.

Figura 2 - Transporte da locomotiva 404 das oficinas da RFFSA ao Bosque da Comunidade

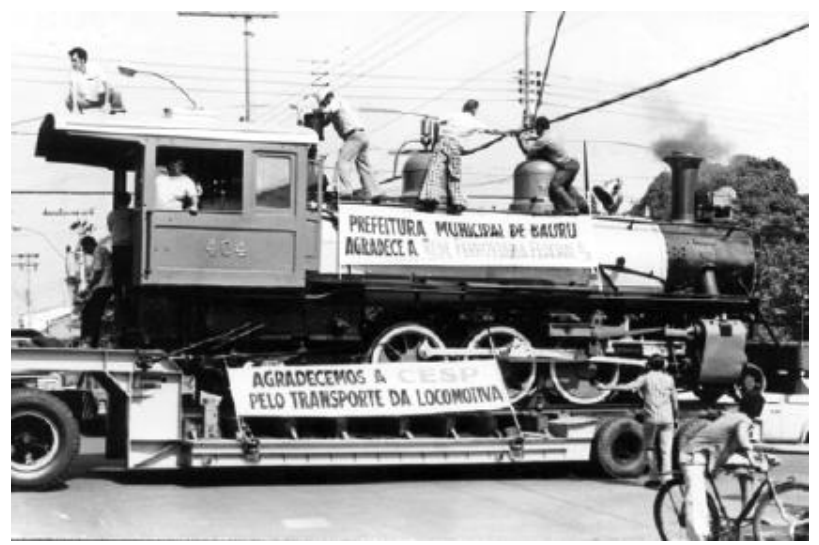

Fonte: Acervo do Museu Histórico Municipal de Bauru, autor não identificado.

Mas é a partir da década de 1980 que as ações de preservação se intensificam, novos equipamentos culturais de preservação são criados e de fato começa a ser desenhada a política pública de preservação que podemos identificar nos dias de hoje.

A experiência adquirida pela USC nos quase 20 anos entre o curso realizado por Vinicius Stein, em 1959, e a inauguração do museu, em 1979, foi decisiva para que a universidade abrisse, quatro anos depois, o Núcleo de Pesquisa e História Gabriel Ruiz Pelegrina (Nuphis). Segundo a universidade, o Nuphis foi criado em 1983, com o objetivo de se tornar um depositário de informações, documentos e coleções relevantes associados à história da cidade, da ferrovia e da região $A$ contribuição de universidades na construção das políticas públicas de preservação também se estende ao curso de graduação em arquitetura da Universidade Estadual Paulista (Unesp) e, mais recentemente, ao seu programa de pós-graduação colaborando com a participação de docentes na criação e composição do Codepac e no desenvolvimento de pesquisas e projetos relacionados à preservação ferroviária.

A Unesp atuou diretamente na preservação da memória ferroviária por meio do Centro de Memória Ferroviária Unesp/RFFSA, que funcionou junto ao MFRB a partir de 1995, com a direção do professor João Francisco Tidei de Lima e de Nilson Ghirardello. Segundo Lima (2017), historiador de formação, o Centro de Documentação e Memória da Unesp o incumbiu de coordenar o projeto de 
recuperação dos documentos da Efnob, que se encontravam "amontoados em depósitos junto aos trilhos da infraestrutura ferroviária em Bauru" (LIMA, 2017, p.1), em conjunto com a Superintendência Regional da RFFSA. Mais tarde, com o apoio da Fundação de Amparo à Pesquisa do Estado de São Paulo (Fapesp), alunos bolsistas contribuíram para a "higienização, separação e catalogação" dos documentos, sendo aberto ao público em 1995 (LIMA, 2017, p.1). O Centro de Memória foi municipalizado no ano de 2008, sendo que todo o seu acervo documental foi incorporado pelo MFRB.

Outra ação que contribuiu para a preservação e para a aproximação das pessoas com a memória ferroviária foi a tentativa de implantar, de forma periódica, um trem turístico no qual o público pudesse vivenciar o funcionamento da chamada composição histórica, composta da locomotiva a vapor n. 278, de 1919, e de carros de passageiros construídos em madeira nas oficinas locais da Efnob nas décadas de 1930 e 1940. A Superintendência Regional de Bauru da RFFSA, em parceria com o Programa de Preservação do Patrimônio Histórico Ferroviário (Preserfe), realizava esporadicamente, no final dos anos 1980 e início dos anos 1990, o projeto "Trem da Integração" (AUDE, 2018). Outra tentativa foi o Convênio n. 156/2001, firmado entre a PMB, Ferrovia Novoeste e Associação Amigos dos Museus, que tinha como objetivo a recuperação do "trem histórico" (Processo n.14.260/01, p. s/n).

Podemos considerar que de fato a implantação de política pública de preservação na cidade de Bauru está associada ao surgimento da primeira estrutura administrativa municipal, especificamente no campo da cultura. Criada no ano de 1985, a Casa da Cultura foi sendo estruturada para atender às demandas de formação, difusão e preservação cultural.No ano de 1987 foi realizado o primeiro concurso público para a composição do quadro permanente de agentes culturais, técnicos de nível universitário com formação em diversas áreas do conhecimento que atuariam nas diferentes funções do novo órgão e, consequentemente, na implantação da nova política cultural do município(BAURU, 1988, p. 6).

Organizada estruturalmente em áreas pertinentes à gestão cultural, a Casa da Cultura passou a atuar no âmbito do patrimônio por meio de uma estrutura administrativa chamada de "área de memória cultural", que, de acordo com o "Relatório Trianual" do órgão, tinha como função "resgatar, organizar e difundir as fontes documentais" (BAURU, 1988, p. 42). Para isso, contava com o MHMB e planejava criar o MFRB, o Arquivo Público Histórico Municipal e o Conselho Municipal 
de Preservação do Patrimônio Histórico e Artístico, Turístico e Ecológico de Bauru (Compphate), sendo que somente o MFRB prosperou.

Mas foi no final da década de 1980 e início da década de 1990 que ocorreram grandes modificações estruturais nas políticas públicas para a cultura na cidade. No ano de 1989, a Casa da Cultura foi incorporada pela recém-criada Secretaria de Cultura, Esporte, Lazer e Turismo, ganhando status de secretaria específica em 1993. É importante ressaltar que a lei que cria a Secretaria de Cultura define duas funções básicas: a primeira é a de "proteger o patrimônio cultural" e a segunda é a de "formular e executar a política cultural do município" (BAURU, 1993, p.2). Para isso, inclui na sua estrutura administrativa dois conselhos, o Codepac e o Conselho de Cultura, além de dois departamentos internos: Ação Cultural e Patrimônio Histórico.

O Plano Diretor (2008)e o Plano de Turismo (2016) são mecanismos de planejamento urbano que complementam a política de preservação local. O primeiro delimita uma área de proteção especial no centro, incluído o pátio ferroviário, diante da existência de imóveis de interesse histórico-cultural mediante seu potencial turístico. O Plano Diretor de Turismo, elaborado mais recentemente, reconhece a prática de seis tipos de turismo no município, dentre eles o turismo histórico cultural, proporcionado pelas unidades museológicas e os prédios tombados, reconhecendo o potencial do complexo ferroviário central como importante atrativo turístico.

A política cultural de proteção ao patrimônio ferroviário da cidade de Bauru constituiu-se principalmente nas décadas de 1980 e 1990. No âmbito nacional, a abertura política e a Constituição de 1988 possibilitaram o surgimento de políticas locais de preservação. No âmbito estadual, as ações se davam nas perspectivas dos museus históricos e da difusão do patrimônio. Já no âmbito local, a política surge em resposta ao anseio de parte específica da sociedade, à estruturação do órgão de cultura e, não menos importante, associada à vontade política dos governos que se sucederam, priorizando mais ou menos a preservação. Essa concentração cronológica nas décadas de 1980 e 1990 fica evidenciada ao ser inserida numa linha temporal, que pode ser visualizada na Figura 3 , que traz o momento de criação de estruturas, leis e programas de preservação. 
Figura 3 - Cronologia da política pública de preservação de Bauru

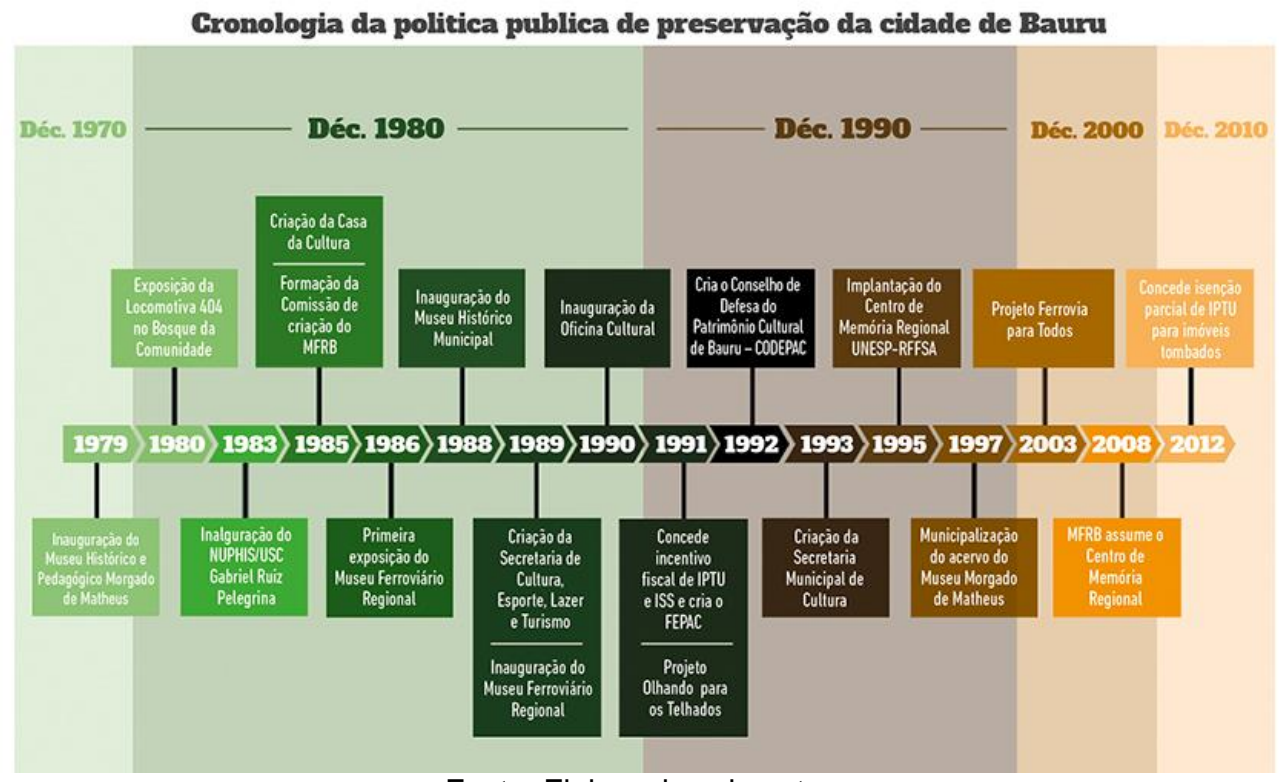

Fonte: Elaborada pelo autor.

\section{Museu Ferroviário Regional de Bauru}

A primeira iniciativa para a implantação do MFRB se deu por parte do executivo por sua recém-criada Casa da Cultura, em 1985, quando um grupo de intelectuais, memorialistas e ferroviários da cidade se encontrou com o prefeito da época para reivindicar a implantação de um museu ferroviário. Esse encontro proporcionou a criação de uma Comissão Especial para Viabilizar a Criação do Museu, composta por 29 membros que tinham a missão de discutir e elaborar as diretrizes que norteariam a implantação do museu. Em seguida, criou-se um grupo de trabalho mais reduzido, que contou com representantes das empresas ferroviárias RFFSA, Ferrovia Paulista S.A. (Fepasa) e do Preserfe, órgão de preservação ligado à RFFSA.

A busca de experiências já consolidadas em museus ferroviários por parte da comissão, de acordo com a documentação pesquisada, pautou-se pelas experiências de Jundiaí e Campinas. Nesse momento, o Preserfe já vinha criando museus nas regiões de atuação da RFFSA (LASMAR, 2017; BEMVENUTI, 2016; MATOS, 2015), além de que estava em curso a primeira ação do Preserfe no estado de São Paulo que culminou com a criação do Centro de Preservação da História Ferroviária do Estado de São Paulo de Paranapiacaba, no ano de 1986 (LEWINSKI, 2017), e o tombamento de todo o seu complexo ferroviário pelo órgão estadual Condephaat, realizado em 1987, situação que gerou muita expectativa e reivindicações da comissão para com o Preserfe (AUDE, 2018). 
A comissão coletivamente decidiu realizar uma exposição de lançamento do futuro museu e deliberou pela criação de rede museológica composta por dois módulos, sendo um para exibir peças de pequeno porte nas instalações da RFFSA e o outro nos armazéns da Fepasa, com exibição de locomotivas e vagões, sendo interligados por uma composição ferroviária histórica (ATA 5, CPIMFB, 1986, p. 2).

A exposição de lançamento do museu foi aberta no dia $1^{\circ}$ de agosto de 1986, em comemoração ao aniversário da cidade. Basicamente foi concebida em módulos distintos, com o acervo histórico de cada uma das empresas ferroviárias e dos sindicatos dos ferroviários existentes na cidade. Segundo Ricardo Nogueira Bogus, museólogo e, na ocasião, coordenador do Museu Ferroviário Barão de Mauá, de Jundiaí, coube a ele fazer a curadoria da exposição relacionada ao acervo Fepasa e ao Preserfe a curadoria do acervo da EFNOB - "não houve reunião prévia para pensar um roteiro único" (BOGUS, 2018, p. 1). Essa situação, além de demonstrar o interesse das empresas em promover e divulgar a sua própria história, ressalta a falta de diálogo e de trabalho conjunto de seus órgãos de preservação, situação que se refletiu na montagem do MFRB, realizado sem a participação da Fepasa.

O trabalho de montagem do MFRB se intensificou logo após a realização de sua primeira exposição. Entre a exposição e a inauguração do museu passaram-se aproximadamente três anos, tempo necessário para que o Preserfe assumisse e realizasse o projeto museológico e para que a superintendência da RFFSA e a PMB realizassem as obras de restauro do prédio e a montagem da exposição do novo MFRB (AUDE, 2018).

Por parte do Preserfe, trabalharam na concepção do projeto a museóloga Telma Lasmar e o arquiteto Sérgio Morais, coordenados por Maria Elisa Carrasoni, diretora responsável pelo órgão (LASMAR, 2017). Segundo a museóloga, os trabalhos de pesquisa sobre a histórica local e a organização e catalogação das peças foram realizados na própria cidade pelo funcionário da Casa da Cultura Gilson Aude (LASMAR, 2017). O órgão de cultura local na ocasião contava com dois estagiários da área de história, que posteriormente vieram a ser contratados. Segundo Aude (2018, p.3), coube a ele "receber as peças, higienizar, catalogar e prepará-las para a exposição, alem de realizar a pesquisa histórica conforme estabelecido pelo projeto".

O primeiro estudo museográfico elaborado pelo Preserfe, existente no MFRB, é composto por um layout com a disposição dos painéis fotográficos com textos explicativos, vitrines e suportes para peças. Porém, resumem-se ao detalhamento dos 
suportes e ao apontamento dos assuntos a serem abordados por meio de fotografias e textos, sem tratar ou definir o acervo tridimensional que seria exposto.Por meio desse estudo, é possível identificar que a linha expositiva se dedicava quase exclusivamente à atuação da RFFSA, tendo em vista que somente foi reservado um painel expositivo para cada uma das outras companhias que atuavam na cidade. A história da ferrovia no Brasilera o ponto inicial da proposta, seguida do destaque dado à comparação do desenvolvimento da cidade antes e depois da chegada da ferrovia.

A análise desse estudo possibilita destacar dois pontos bem particulares. $O$ primeiro está ligado à questão indígena, tratada na museografia, mas de forma superficial e desacertada, destacando a etnia Kaingang, povo originário da região, somente após o processo de "pacificação", em detrimento da real história dos grandes conflitos e extermínio destes no processo de construção da ferrovia no Oeste Paulista. Por seguinte, a ideia defendida por muitos da comissão inicial, de criação de um museu do trabalhador ferroviário, não se concretiza. A linha expositiva pautou-se pela exaltação da empresa estatal ferroviária como a maior ação do governo federal na cidade de Bauru.

A gestão do MFRB em seu início foi realizada por um conselho com característica deliberativa de forma tripartite, ou seja, colegiado composto por representantes das duas empresas ferroviárias, RFFSA e Fepasa, e da Casa da Cultura, por parte da Prefeitura Municipal. As cadeiras do executivo foram preenchidas por dois conselheiros ligados à preservação e um funcionário da Casa da Cultura. Por parte das empresas, as indicações contavam com a participação de funcionários da superintendência local.

A precarização das empresas estatais ferroviárias ocorrida no país, que culminou nos anos de 1990 com o processo de privatização, atingiu as duas empresas atuais que operavam em Bauru, proporcionando ao MFRB uma nova configuração de gestão. Ao contrário das estatais, as concessionárias que vieram operar o transporte ferroviário local não apresentaram até então nenhuma política de preservação ferroviária, situação que afetou todos os museus criados pelo Preserfe, ocasionando inclusive o fechamento de muitos deles (LASMAR, 2017).

O conselho gestor,originalmente formado pelas empresas ferroviárias, nunca mais foi recomposto, cabendo à Secretaria Municipal de Cultura (SMC) realizar sua gestão. Dessa forma, naturalmente o MFRB foi municipalizado, mesmo que até o presente não tenha havido nenhuma atualização da legislação diante da nova 
configuração. Suas atividades estão relacionadas a exposições permanentes, auxílio à pesquisa e atividades de ação cultural e educativas. Seu acervo é composto por peças diversas de grande e de pequeno porte, associadas ao sistema produtivo da indústria ferroviária local, farta documentação, além dos edifícios históricos que abrigam toda a sua estrutura funcional.

\section{Conselho de preservação do patrimônio cultural de Bauru}

Os conselhos de preservação tornaram-se órgãos representativos importantes de elaboração, discussão e aplicação de políticas públicas na área social. Foi a Constituição de 1988 que possibilitou de fato o estabelecimento dessa política de representação social com base na regulamentação e institucionalização de conselhos. Isso quebrou de certa forma o protagonismo exclusivo do Estado na elaboração de políticas públicas. Com o passar dos anos, os conselhos se multiplicaram e se diversificaram em diferentes áreas, como no caso do patrimônio cultural, implantado em vários estados e municípios.

Dentre os recursos de proteção do patrimônio, o tombamento é a principal ferramenta para garantir a preservação de bens móveis e imóveis da cidade de Bauru, no que diz respeito à sua "história, folclore e arquivologia", e que sejam revestidos de "valores artístico-culturais" (BAURU, Lein. 3.545, 1993). Também se garante a proteção de áreas envoltórias e de conjuntos arquitetônicos. Espacialmente, os bens listados para preservação concentram-se na região central e na zona sul da cidade, sendo que as exceções são os casarões de fazenda e as estações ferroviárias, na zona rural.

A concepção da lei de criação do Codepac levou em conta a experiência já praticada nos municípios do estado, como Piracicaba, Santos (GHIRARDELLO, 2017), Campinas e São Paulo (BARBEIRO, 2016), como também contou com o auxílio de "pessoas ligadas ao CONDEPHAAT da área do patrimônio, como arquitetos, urbanistas e historiadores"(BARBEIRO, 2016).

Uma das principais motivações para a criação do conselho local estava associada às intensas transformações da área central nos anos de 1980 e início dos anos 1990, diante da remodelação da Praça Rui Barbosa e da construção do calçadão da Rua Batista de Carvalho, situação que proporcionou "especulação imobiliária na região central", colocando em risco muitos prédios antigos, conforme relatou o primeiro 
presidente do Codepac (GHIRARDELLO, 2017, p. 2). Junto a isso, estava em curso o processo de concessões do transporte ferroviário, que já dava sinais de ociosidade e abandono das estruturas ferroviárias existentes no centro da cidade.

Essa situação também foi justificada pelo vereador proponente da lei de criação do Codepac, que, após voltar de um longo período residindo fora de Bauru, observou a intensidade das transformações ocorridas principalmente na década de 1980, conforme esclarece.

[...] quando eu voltei, senti que a cidade teve um crescimento muito grande, a cidade foi ficando meio impessoal e senti a necessidade de segurar um pouco isso aí, evitar que esse desenvolvimento acabasse afastando a história da cidade, principalmente este eixo ferroviário e estas coisas ligadas à história da cidade (BARBEIRO, 2016, p. 2).

A característica pública do patrimônio ferroviário, impactando de forma mais amena o direito de propriedade e diante das severas incertezas quanto à sua destinação, acabou contribuindo favoravelmente para a implantação do recurso do tombamento, conforme Ghirardello (2017) esclarece sobre a movimentação pela sua criação por segmentos sociais.

\footnotetext{
Entendo que houve um movimento mais ligado aos intelectuais da academia e mesmo alguns ferroviários, nada grandioso. Lembro que era um período onde a ferrovia estava em vias de ser privatizada e sempre havia questionamentos sobre o que seria dos seus prédios (GHIRARDELLO, 2017, p. 3).
}

As diretrizes iniciais estabelecidas pelo Codepac estavam baseadas na preservação de cinco tipologias. A primeira era oriunda do núcleo urbano originário, sendo que para isso buscou-se preservar bens que estivessem associados às "construções coloniais de influência mineira" (ATA 1, 1996, p.1).Foi seguida pela tipologia ferroviária, farta diante da chegada da ferrovia à cidade na primeira década do século XX e pela arquitetura eclética diante de edifícios públicos como "10 Grupo Escolar", "Santa Casa" e o "Hospital Beneficência Portuguesa" (ATA 1, 1996. p.1). Outras tipologias que também se buscaram preservar foram os edifícios de estilo "art déco", além dos imóveis com características arquitetônicas genéricas, que, de acordo com a Ata da 1a reunião ordinária (1996, p.1), denominavam-se "outros", como o conjunto arquitetônico do Aeroclube e a Igreja Tenrikyo. 
O jornal Diário de Bauru de 18 de dezembro de 1996 (1996, p. 7) traz uma matéria sobre a entrega simbólica, por parte dos conselheiros do Codepac, de 32 processos de tombamento ao prefeito municipal. A matéria explica que 24 deles já se encontravam finalizados, em condições de proceder ao tombamento definitivo por parte do prefeito. A matéria ressalta o trabalho "exaustivo" realizado pelos conselheiros na elaboração do conjunto de documentos, tendo em vista o interesse do prefeito em concluir os tombamentos antes do término do seu mandato, naquele ano. Porém, observou-se que nenhum bem foi tombado pela referida gestão municipal, que findou no ano de 1996. O primeiro bem tombado foi a Estação da Efnob, em 1999.

Depois de promulgada a legislação de criação do Codepac, somente na gestão do prefeito seguinte ela enfim foi regulamentada e o conselho empossado no dia 26 de março de 1996.A composição do Codepac se dá por representantes da Secretaria de Cultura, responsável pela gestão administrativa do órgão, e pelas secretarias do Planejamento e Jurídica. As universidades estão representadas pela Unesp e USC. Representando as entidades de classe, participam a Ordem dos Advogados do Brasil, a Associação dos Geógrafos Brasileiros, a Associação dos Engenheiros, Arquitetos e Agrônomos e o Instituto de Arquitetos do Brasil. Também compõem o conselho a Associação Amigos dos Museus. Atualmente, o conselho não se encontra constituído e a Câmara Municipal analisa projeto de alteração da lei enviado pelo executivo. A última gestão encerrou seus trabalhos no ano de 2016 (SANCHES, 2017).

Quando analisamos o conjunto dos bens tombados na perspectiva de suas funções de origem, identificamos que representam as principais atividades sociais e econômicas praticadas na cidade, como a religiosa, educacional, comercial, pública, ferroviária, de moradia,entre outros, situação levada em conta independentemente do seu valor arquitetônico. Nessa perspectiva, intencional ou não por parte do conselho, o que se verifica é que a preservação de elementos imateriais acaba se dando de forma indireta, quando a escolha dos bens tombados estava associada muito mais ao significado da sua função original na cidade do que aos seus elementos arquitetônicos. Diante disso, torna-se muito importante que os procedimentos de tombamento estejam também embasados por inventários e testemunhos imateriais, mesmo porque que a legislação local não prevê a preservação do patrimônio imaterial.

Podemos destacar os bens ferroviários protegidos pelo conselho local como sendo aqueles já tombados (Tabela 1) e aqueles que se encontram ainda em andamento (Tabela 2). 
Tabela 1 - Bens ferroviários tombados até o presente

\begin{tabular}{llll}
\hline Processo & Bem & Uso original & Decreto \\
\hline $18.041 / 96$ & Antiga Casa do Superintendente da NOB & Moradia & $9.459 / 2003$ \\
$18.030 / 96$ & Estação Central da NOB & Estação & $8.617 / 1999$ \\
$18.049 / 96$ & Estação da Cia Paulista de Estrada de Ferro & Estação & $8.860 / 2000$ \\
$18.027 / 96$ & Estação Sorocabana & Estação & $9.922 / 2004$ \\
$30.300 / 03$ & Estação Curuçá & Estação & $9.977 / 2005$ \\
$30.300 / 03$ & Estação Val de Palmas & Estação & $9.979 / 2005$ \\
$30.300 / 03$ & Estação de Tibiriçá & Estação & $9.978 / 2005$ \\
$31.796 / 01$ & Carro-restaurante; Locomotiva a vapor 278; Chassi e rodeiros; Carro & Rodantes e diversos & $11.442 / 2001$ \\
& de passageiro; 3 Carros-dormitórios; Locomotiva a vapor - № 01; & & \\
& Locomotiva a vapor - № 404; Todo o acervo do Museu Ferroviário. & & \\
\hline
\end{tabular}

Fonte: Elaborada pelo autor com base em MHMB (2014).

Tabela 2 - Bens ferroviários em estudo de tombamento

\begin{tabular}{lll}
\hline Processo & Bem & Uso original \\
\hline $2.497 / 03$ & Sociedade Beneficente 19 de Junho & Escritório \\
$33.626 / 07$ & Estação Ferroviária Triagem Paulista & Estação \\
$6.051 / 10$ & Carros e locomotivas 31 bens & Patrimônio Operacional \\
$10.564 / 10$ & Complexo da Paulista & Conjunto Ferroviário \\
$15.330 / 10$ & Complexo Ferroviário Central & Conjunto Ferroviário \\
$10.672 / 02$ & Locomotivas Elétricas e carros de passageiros & Patrimônio Operacional \\
$21.427 / 10$ & Colônia da Sorocabana & Residência \\
$53.422 / 13$ & Bens Ferroviários - NOB - Jaguariúna & Patrimônio Operacional \\
$30.116 / 13$ & Horto de Aymores & Fazenda
\end{tabular}

Fonte: Elaborada pelo autor com base em MHMB (2014).

\section{Considerações finais}

Por meio de uma perspectiva mais ampla, podemos considerar que a preservação em Bauru se coloca como exemplo característico proporcionado pelas políticas públicas desenvolvidas pelos órgãos federal e estadual nos anos 1980. Ou seja, é um reflexo das práticas, ações, ideologias e acontecimentos ocorridos num período significativo da história recente do Brasil, proporcionado pela abertura política, pelas novas diretrizes de preservação e diante do desejo e envolvimento da sociedade em atuar no processo de reconhecimento do seu próprio patrimônio histórico, baseado no reconhecimento de suas múltiplas identidades (CURY, 2002; AGUIAR, 2015; MINC, 2016). 
No contexto da ideologia política presente nos processos de preservação no Brasil, observa-se uma semelhança entre as práticas e objetivos buscados pelos diferentes entes públicos. Enquanto a política nacional buscou ressaltar os fatos memoráveis para a construção de um Estado Nacional (RUBIM, 2007; CURY, 2002), o estado de São Paulo buscou demarcar a sua identidade bandeirante e republicana (MISAN, 2008; RODRIGUES, 1999). O município de Bauru vem reafirmar a sua origem associada à expansão do interior paulista e o seu caráter desenvolvimentista, resultado da presença fortíssima do Estado Nacional por meio da RFFSA, que proporcionou o desenvolvimento urbano e econômico da cidade, com base no capital agrário e industrial (OLIVEIRA, 2011; LIMA, 2017; GHIRARDELLO, 2017; POSSAS, 2017).

As diretrizes da preservação no Brasil baseadas tradicionalmente no monumento influenciaram de forma significativa as políticas públicas do setor, em que a arquitetura monumental ainda é o objeto mais lembrado quando se trata da escolha oficial do bem a ser considerado suporte de determinadas memórias. Atualmente, no caso ferroviário, essa característica é facilmente identificada, quando os principais elementos preservados tornaram-se as estações, seguidas pelos grandes elementos arquitetônicos que compõem os conjuntos ferroviários, como rotundas, oficinas e outros (OLIVEIRA, 2010b; MORAES, 2016; KÜHL, 2008). Mas também é de se destacar a prática de preservação de determinadas tecnologias precursoras desse modal de transporte, como é o caso das locomotivas a vapor, que atraem muito público quando estão na condição de acervo, expostas em museus ou em circuitos turísticos, como visto em Bauru.

É possível constatar que a política de preservação praticada pelo governo do estado no campo museal foi estruturada e disseminada por objetivos educacionais e turísticos nos municípios paulistas, enquanto o tombamento se resumiu às iniciativas do Condephaat. Sem uma política de apoio para que os municípios implementassem ações locais de preservação, restou reivindicar que o conselho estadual reconhecesse seu patrimônio local ou partir para iniciativas próprias.

No âmbito dos mecanismos de proteção, o tombamento e os museus se tornaram as práticas mais empregadas pelos municípios paulistas para atender diretamente a demandas e perspectivas locais (LOSNAK; OLIVEIRA, 2016). Estes se colocam de certa forma como únicos recursos que permitiram à sociedade atual 
reconhecer seu processo de origem, por meio da identificação de elementos materiais e imateriais que expressam a sua diversidade identitária (CANCLINI, 2008).

A preservação ferroviária no município tem suas ações iniciais em meados dos anos de 1970 por meio de ações isoladas, como o processo de patrimonialização da locomotiva 404 e da n. 1. A política pública de preservação começa mesmo a ser colocada em prática em meados dos anos de 1980, com a criação da Casa da Cultura por iniciativa local e do MFRB, que foi parte da política de preservação promovida pela RFFSA em vários municípios brasileiros onde atuava (BEMVENUTI, 2016; MATOS, 2015). Essa situação se assemelha às práticas realizadas pela União e pelo governo do estado, que iniciaram sua política de preservação por meio de ações pontuais que foram, com o tempo, sendo sistematizadas e se transformando em políticas públicas.

Desde a sua origem, os recortes temáticos trazidos pela museografia do MFRB seguiram aqueles concebidos pelo Preserfe, que no seu conjunto destacam a atuação da empresa ferroviária federal como agente do desenvolvimento de regiões até então não ocupadas. Diante dessa constatação, podemos concluir que, mesmo depois das modificações mais recentes da museografia realizada pela SMC, a questão ferroviária apresentada pelo MFRB pouco está associadaà história de Bauru, que teve o seu desenvolvimento basicamente proporcionado pela empresa federal.

Quanto ao Codepac, podemos considerar que várias condicionantes influenciaram a sua criação. A princípio, a remodelação pela qual o centro originário da cidade passou no final dos anos de 1980 provocou preocupação principalmente em pessoas ligadas à área da preservação e em parte dos meios de comunicação local, sobre a real necessidade de se criarem mecanismos e critérios de proteção oficiais no município. No contraponto, as transformações urbanas estavam sendo realizadas pelo próprio executivo, portanto, esse fato esclarece porque a criação do Codepac só contou com a participação do legislativo e de segmentos da comunidade. O executivo, na ocasião, absteve-se da participação de todo o processo de criação do conselho, que só foi colocado em prática na gestão subsequente.

A percepção proporcionada pela vivência diante do objeto deste trabalho mostra que a representação física e simbólica do patrimônio ferroviário local é muito evidente e forte na cidade de Bauru ainda hoje, seja diante da imponência dos seus edifícios, das grandes áreas que ocupa no centro e nos seus arredores, como também por estar presente na memória de muitos trabalhadores da ferrovia e daqueles que vivenciaram o pleno funcionamento do transporte ferroviário na cidade. 


\section{Referências}

\section{Fontes primárias: Legislação}

BAURU. Lei Municipal n. 3545, de 15 de março de 1993.

BRASIL. Constituição da República Federativa do Brasil 1988. 9. ed. São Paulo: Revista dos Tribunais, 2004. 315 p.

\section{Documentos e processos}

BAURU. Prefeitura Municipal. Celebração de Convênio. Processo n. 14260/01. Bauru: SMC, 2001.

BAURU. Prefeitura Municipal. Casa da Cultura: 3 anos democratizando a cultura. Relatório de Atividades de julho de 1985 a julho de 1988.

CODEPAC. Bauru. Ata da 1ª Reunião Ordinária de 26 de março de 1996, 1-2.

CPIMFB - Comissão Provisória para Instalação do Museu Ferroviário de Bauru. Ata da 5를 Reunião de 2 de abril de 1986, 1-4.

MHMB. Museu Histórico Municipal de Bauru. Controle de entrada e saída de processos do Codepac. Elaborado em abril de 2014.

PMB. Prefeitura Municipal de Bauru. Painel informativo anexo à locomotiva 404, no Bosque da Comunidade de Bauru, 2017.

\section{Entrevistas}

AUDE, Gilson Miguel. A criação do MFRB [19 fev. 2018]. Entrevista concedida a Sérgio Losnak.

BARBEIRO, Veríssimo. Codepac [10 fev. 2016]. Entrevista concedida a Sérgio Losnak.

\section{Mensagens eletrônicas}

BOGUS, R. N. Exposição inaugural do MFRB [mensagem pessoal]. Mensagem recebida por "sergiolosnak@gmail.com" em 6 fev. 2018.

GHIRARDELLO, N. A criação do Codepac [mensagem pessoal]. Mensagem recebida por "sergiolosnak@gmail.com"em 14 nov. 2017.

LASMAR, T. Atuação do Preserfe em Bauru [mensagem pessoal]. Mensagem recebida por "sergiolosnak@gmail.com"em 27 out. 2017.

LIMA, J. F. T. O Centro de Memória Ferroviária [mensagem pessoal]. Mensagem recebida por "sergiolosnak@gmail.com"em 8 nov. 2017.

POSSAS. L. M. V. A criação do Codepac [mensagem pessoal]. Mensagem recebida por "sergiolosnak@gmail.com" em 23 nov. 2017.

SANCHES, A. G. Benefício fiscal a proprietários de bens tombados [mensagem pessoal]. Mensagem recebida por "sergiolosnak@gmail.com" em 23 out. 2017.

Fontes secundárias: Livros, teses e artigos

AGUIAR, L. B. Reflexões sobre estados nacionais e a criação das agências de preservação dos patrimônios culturais. Conhecimento e Diversidade, Niterói, v. 7, n. 13, p. 79-89, jan./jun. 2015.

AZEVEDO, E. B. Patrimônio industrial no Brasil. Revista da USJT - Arquitetura e Urbanismo, n. 3, p. 11-22, 2010.

BARBALHO, A. Política cultural. Salvador: P55 Edições, 2013. 
Políticas culturais no Brasil: identidade e diversidade sem diferença. In: RUBIM, A. A. C.; BARBALHO, A. (Org.). Políticas culturais no Brasil. Salvador: Edufba, 2007. 179 p.

BEMVENUTI, A. Gestão de museus: comunicação e público - estudo sobre o Museu do Trem, São Leopoldo, RS (2009-2012). 2016. Dissertação (Mestrado em Museologia)-Programa de Pós-Graduação em Museologia, Universidade de São Paulo, São Paulo, 2016.

BOTELHO, I. A política cultural \& o plano das ideias. In: RUBIM, A. A. C.; BARBALHO, A. (Org.). Políticas culturais no Brasil. Salvador: Edufba, 2007.

CANCLINI, N. G. Culturas híbridas. São Paulo: Editora USP, 2008.

COELHO, T. Dicionário crítico de política cultural. 2. ed. São Paulo: lluminuras, 1999.

CURY, C. E. Políticas culturais no Brasil:subsídios para construção de brasilidades. 2002. 160 f. Tese (Doutorado em Educação)-Faculdade de Educação da Universidade Estadual de Campinas, Campinas, 2002.

GHIRARDELLO, N. Aspecto do direcionamento urbano da cidade de Bauru. 1992. Dissertação (Mestrado)-Escola de Engenharia de São Carlos, Universidade de São Paulo, São Carlos, 1992.

KÜHL, B. M. Preservação do patrimônio arquitetônico da industrialização. São Paulo: Ateliê Editorial, 2008.

LEWINSKI, C. I. K. O que é o Preserve/fe? E como se constituiu o Centro de Preservação da História Ferroviária do Rio Grande do Sul na década de 1980? Revista Mosaico, v. 8, n. 12, p. 103-122, 2017.

LOSNAK, S. R.; OLIVEIRA, E. R. Políticas públicas de preservação nos municípios paulistas: museus e conselhos. In: PASCHOARELLI, L. C.; SALCEDO, R. F. B. (Org.). Design, arquitetura e urbanismo: transversalidades. Bauru: Canal 6, 2016. p. 206-226.

MATOS, L. F. Memória ferroviária: da mobilização social à política pública de patrimônio. 2015. Tese (Doutorado em História, Política e Bens Culturais)-Fundação Getulio Vargas, Rio de Janeiro, 2015.

MISAN, M. Os museus históricos pedagógicos do estado de São Paulo. Anais do Museu Paulista, São Paulo, v. 16, n. 2, p. 175-205, jul./dez. 2008.

MORAES, E. H. Os bens ferroviários nos tombamentos do Estado de São Paulo:1969-1984. 2016. 127 f. Dissertação (Mestrado)-Programa de Pós-Graduação em Arquitetura e Urbanismo da Faculdade de Arquitetura, Artes e Comunicação da Universidade Estadual Paulista "Júlio de Mesquita Filho", Bauru, 2016.

OLIVEIRA, E. R. Patrimônio ferroviário do estado de São Paulo: as condições de preservação e uso dos bens culturais. Projeto História (PUCSP), n. 40, p. 179-203, 2010a.

Museus ferroviários do estado de São Paulo (Brasil): as políticas de conservação e o estado atual do patrimônio ferroviário brasileiro. TST Transportes, Servicios y Telecomunicaciones, n. 19, p. 190-204, 2010b.

Museus e ferrovia: estudo sobre a preservação do patrimônio ferroviário paulista. Revista Labor e Engenho, v. 5, n. 3, p. 20-31, 2011.

RODRIGUES, M. Imagens do passado: a instituição do patrimônio em São Paulo 1969-1987. São Paulo: Unesp, 1999. 
RUBIM, A. A. C. Políticas culturais no Brasil: tristes contradições, enormes desafios. In: RUBIM, A. A. C.; BARBALHO, A. (Org.). Políticas culturais no Brasil. Salvador: Edufba, 2007. $179 \mathrm{p}$.

SALCEDO, R. F. B. Gestão do Codepac na preservação do patrimônio cultural: arquitetura moderna em Bauru-SP. In: SEMINÁRIO DOCOMOMO BRASIL: INTERDISCIPLINARIDADE E EXPERIÊNCIAS EM DOCUMENTAÇÃO E PRESERVAÇÃO DO PATRIMÔNIO RECENTE, 9., 2011, Brasília. Anais... Brasília, 2011.

SANT'AGOSTINHO, L. H. F. Bauru, chão de passagem: entreposto de valores na rota Atlântico-Pacífico. 1995. Dissertação (Mestrado)-Faculdade de Arquitetura e Urbanismo, Universidade de São Paulo, São Paulo, 1995.

SILVA, A. Roteiro histórico: uma cidade e uma instituição. Bauru: Tipografia Comercial, 1957.

\section{Matérias jornalísticas}

A HISTÓRIA reconta a história. Jornal da Cidade, Bauru, 12 out. 1991.

BAURU precisa apoiar o seu museu histórico. Jornal da Cidade, Bauru, p. 28, 15 jul. 1979b.

BAURUENSE pode conhecer a história da ferrovia. Diário de Bauru, Bauru, p. 6, 27 ago. 1989.

BAURUENSES continuam doando relíquias ao Morgado Matheus. Jornal da Cidade, Bauru, p. 3, 1 e 2 ago. 1979a.

CALÇADÃO da Batista de Carvalho. Diário de Bauru, Bauru, p. 7, 18 dez. 1996.

CHUVA não impede festa no Bosque da Comunidade. Jornal da Cidade, Bauru, p. 5, 23 ago. 1980.

COM a presença de secretários o museu será inaugurado no dia 1‥ Jornal da Cidade, Bauru, p. 5, 28 jul. 1979d.

DOADO ao nosso museu o primeiro diploma de bauruense. Jornal da Cidade, Bauru, p. 17, 22 jul. 1979c.

DOADOS jornais antigos para o museu bauruense. Jornal da Cidade, Bauru, p. 25, 29 jul. 1979e.

O FUTURO Museu de Bauru. Revista Realce, Bauru, p. 30-31, 1969.

OFICINA Cultural será inaugurada hoje. Diário de Bauru, Bauru, p. 1, 5 jun. 1990.

Documentos eletrônicos

MHMB, 2017. Um pouco da história do museu. Disponível em: <http://hotsite.bauru.sp.gov.br/museuhistorico/historia.aspx>. Acesso em: 22 out. 2017. MINISTÉRIO DA CULTURA. Plano Nacional de Cultura: principais momentos de uma construção democrática. Disponível em: <http://pnc.culturadigital.br/plano-nacional-decultura-principais-momentos-de-uma-construcao-democratica/>. Acesso em: 12 set. 2016.

USC, 2017. Disponível em: <https://www.usc.br/na-usc/nuphis>. Acesso em: 21 nov. 2017. 